\title{
Non-Proliferative Diabetic Retinopathy
}

National Cancer Institute

\section{Source}

National Cancer Institute. Non-Proliferative Diabetic Retinopathy. NCI Thesaurus. Code C35668.

An early stage of diabetic retinopathy that is characterized by retinal hemorrhage and exudate, but without proliferation of the blood vessels. 